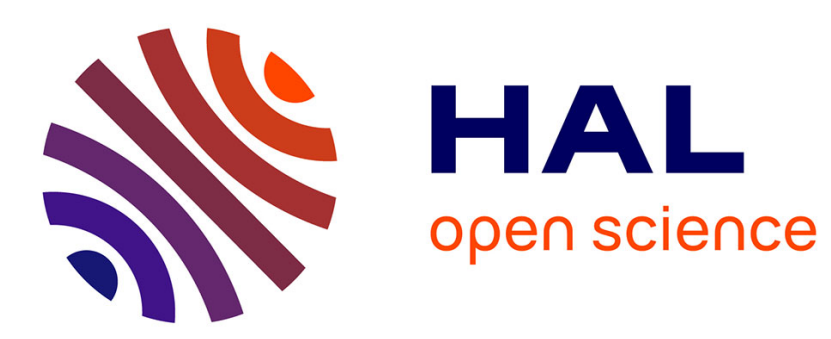

\title{
Optical Absorption Microspectroscopy ( $\mu$-OAS) Based on Schwarzschild-Type Cassegrain Optics
}

Mathieu Chassé, Gérald Lelong, Peter van Nijnatten, Ivo Schoofs, Jürgen de Wolf, Laurence Galoisy, Georges Calas

\section{- To cite this version:}

Mathieu Chassé, Gérald Lelong, Peter van Nijnatten, Ivo Schoofs, Jürgen de Wolf, et al.. Optical Absorption Microspectroscopy ( $\mu$-OAS) Based on Schwarzschild-Type Cassegrain Optics. Applied Spectroscopy, 2015, 69 (4), pp.457-463. 10.1366/14-07628 . hal-01591205

\section{HAL Id: hal-01591205 https://hal.science/hal-01591205}

Submitted on 21 Sep 2017

HAL is a multi-disciplinary open access archive for the deposit and dissemination of scientific research documents, whether they are published or not. The documents may come from teaching and research institutions in France or abroad, or from public or private research centers.
L'archive ouverte pluridisciplinaire HAL, est destinée au dépôt et à la diffusion de documents scientifiques de niveau recherche, publiés ou non, émanant des établissements d'enseignement et de recherche français ou étrangers, des laboratoires publics ou privés. 


\title{
Optical Absorption Microspectroscopy ( $\mu$-OAS) Based on Schwarzschild-Type Cassegrain Optics
}

Mathieu CHASSÉ ${ }^{1}$, Gérald LelONG ${ }^{1}$, Peter van NiJNATTEN², Ivo SCHOOFS², Jürgen de WOLF², 5 Laurence GALOISY $^{1}$ and Georges CALAS ${ }^{1}$

${ }^{1}$ Institut de minéralogie, de physique des matériaux et de cosmochimie (IMPMC) - Sorbonne Universités - Université Pierre et Marie Curie Paris 06 - CNRS UMR 7590 - IRD UMR 206 Muséum national d'Histoire naturelle, 4 Place Jussieu, F-75005 Paris, France

${ }^{2}$ OMT Solutions BV, High Tech Campus 9, 5656AE Eindhoven, Netherlands

\begin{abstract}
A new experimental setup, combining a custom designed Schwarzschild-type Cassegrain-based microscope and a UV-visible-near IR spectrophotometer, has been developed, focusing the light beam down to $20 \mu \mathrm{m}$ diameter. Optical absorption spectra (in the $300-2500 \mathrm{~nm}$ range) have been measured on micron-sized natural glass inclusions providing information on iron speciation in magmatic melts. The absence of contribution from the host crystal matrix provides a test of the efficiency of microfocusing. A microthermometric stage has been adapted on the microscope for measuring optical absorption spectra up to $900 \mathrm{~K}$ with application to the thermochromism of minute natural spinel crystals $\left(\mathrm{MgAl}_{2} \mathrm{O}_{4}: \mathrm{Fe}^{2+}, \mathrm{Cr}^{3+}\right)$. This experimental setup

20 provides an easy and fast way to follow the evolution of spectral properties and color of glasses or crystals with temperature as well as the possibility of measuring spatially resolved optical absorption spectra.
\end{abstract}

Keywords: optical absorption spectroscopy, OAS, UV-visible-near IR spectroscopy,

25 microspectrophotometry, Cassegrain microscope, glass inclusions, temperature, spinel.

\section{Introduction}

Microspectroscopy has been widely developed on various spectroscopic techniques as it

30 brings spatially resolved information. In the case of optical absorption spectroscopy (OAS), even if most efforts have been devoted to microspectroscopy in the IR range ${ }^{1,2}$, common microscopes have been adapted on portable or home-made spectrophotometers in order to give access to the UVvisible range for various applications, e.g. in biology to identify and/or map DNA or pigments ${ }^{3,4}$ or in forensic sciences ${ }^{5}$. UV-visible microspectroscopy was also used in chemistry and material 
35 sciences $^{6}$ but spatial resolution, spectral range and detection limits were more limited than for standard laboratory spectrophotometers. In Earth sciences, in situ high-temperature visible microspectroscopy has been developed to study temperature-induced color change kinetics of volcanic materials ${ }^{7}$. In the specific case of transition elements, an extended wavelength range is required to investigate their spectroscopic properties in microscopic samples, as electronic transitions span a broad range in energy. Recent studies have shown the interest of developing specific microspectrophotometers or adapting microscope on laboratory spectrophotometers. For instance, optical absorption microspectroscopy ( $\mu$-OAS) in a reflection mode has been developed recently in the range $400-1,600 \mathrm{~nm}^{8}$. In a transmission mode, some examples of home-made adaptations of optical microscopes on a UV-visible-near IR spectrophotometer were also reported ${ }^{9,10}$ with the IR and visible regions being measured separately. Then, there is a need for versatile microscopes designed for OAS measurements, working from UV to NIR without chromatic aberrations and allowing spatially resolved OAS, with possible variable temperature and/or pressure environment.

Here, the development of a versatile microspectrophotometric technique, allowing 50 measurement of optical absorption spectra routinely in a wide range $(200-3,300 \mathrm{~nm})$ is reported. Unlike a typical optical microscope with an optic based on glass lenses that absorb a large portion of light and exhibit chromatic aberration for such a large wavelength range, this spectrophotometerfitted microscope features an all-reflective optics, which, besides the UV and visible spectral ranges, ensures the coverage of the entire IR spectral range $\left(\sim 50-10,000 \mathrm{~cm}^{-1}\right)$ with a minimal loss of the signal. The central elements are a pair of reflective condensing objectives with a Schwarzschild-type Cassegrain design (NA = 0.54), which focus the light to samples, and then collect the transmitted light from the samples. It allows to record spatially resolved spectra with a beam diameter ranging from 20 to $120 \mu \mathrm{m}$, and may be coupled with a heating stage for investigations at variable temperature. This Cassegrain microscope was designed to fit into the sample compartment of a double-beam UV-Visible-NIR spectrophotometer. The efficiency of the setup is illustrated by two $\mu$-OAS studies: (i) spectral measurements of micrometer-sized volcanic glass inclusions trapped in an olivine $\left(\mathrm{Mg}_{2} \mathrm{SiO}_{4}: \mathrm{Fe}^{2+}\right)$ crystal in order to show the feasibility of measuring $\mu$-optical absorption spectra down to $20 \mu \mathrm{m}$; and (ii) high-temperature $\mu$-OAS measurements of spinel crystals using a microthermometric stage, in order to test the versatility, the 65 wider wavelength range and the extended temperature range brought by this setup, in comparison with previous studies ${ }^{11}$. 
The experimental setup is based on a custom designed Cassegrain-type microscope (Fig. 1, a), used to get spatially resolved optical absorption spectra without any chromatic aberrations, mounted in the sample compartment of a UV-visible-near IR spectrophotometer (PerkinElmer®)

75 LAMBDA 1050). Measurements are performed using well-defined measurement geometry. The beam is randomly polarized with incident angles evenly distributed in the range $17.3^{\circ}-32.7^{\circ}$. The average angle of incidence is $25.0^{\circ}$. The polarization of the incident beam is random. The microscope allows work in transmission mode with a measurement spot diameter ranging from 20 to $120 \mu \mathrm{m}$. The sample beam at the entrance port of the sample compartment of the

80 spectrophotometer (coming from the monochromator) is redirected using flat mirrors towards a spherical mirror just above the upper Schwartschild objective. The all reflective optics is coated with UV enhanced aluminum. Only half of the spherical mirror of the upper Cassegrain objective is employed to focus the beam on the sample (Fig. 1, b, red beam). The other half is used in another version of the microscope to recover the beam reflected by the sample. The transmitted light, which

85 is recovered by the lower Cassegrain objective (Fig. 1, b, blue light beam), is passed to a spherical mirror and redirected towards the spectrophotometer detector by a series of flat mirrors.

In optical systems, energy conservation is defined by the so-called Helmholtz-Lagrange invariant, which roughly states that image area multiplied by solid angle is constant throughout the system, considering only rays that can pass through the system. Light input at the entrance of the

90 microscope is a build-in adjustable aperture which, at maximum opening provides a beam that has the approximate size of $6 \times 10 \mathrm{~mm}$ (width $\times$ height) and a beam solid angle of about $0.0062 \mathrm{sr}$. The magnification of the microscope is 80 times and the total solid angle of the beam at the sample is roughly $0.356 \mathrm{sr}$. Since the beam area at the entrance of the microscope is $80 \times 80=6,400$ times larger, the solid angle of the beam accepted at the entrance of the microscope is 6,400 times smaller, namely $0.0000556 \mathrm{sr}$. The maximum energy throughput due to the Helmholtz-Lagrange invariant (not counting reflection losses by the reflecting surfaces in the optical path) is $0.0000556 / 0.0062=$ $0.9 \%$, with a spot size of $75 \times 125 \mu \mathrm{m}$.

Aluminum coated mirrors have reflection values in the range $85 \%-97 \%$, depending on the wavelength. The minimum reflection of $85 \%$ occurs around $830 \mathrm{~nm}$ and at $860 \mathrm{~nm}$, the wavelength 100 where the spectrophotometer has its lowest sensitivity. The beam reflects 14 times on mirrors in the microscope. Taking into account the Helmholtz-Lagrange invariant, the maximum energy throughput (with maximum beam aperture) lies in the range $0.09 \%-0.59 \%$ depending on the wavelength. The signal/noise ratio is improved by beam equalizing optics in the reference beam, using a set of 14 mirrors with the same reflection losses as in the sample beam and a second 
adjustable aperture.

The microscope is equipped with a CCD-camera and optics providing an image of the sample position through the upper Cassegrain objective. This is used to visualize the beam on the sample during the manual focusing (changing the distance between sample and upper objective). By switching camera optics, a reduced image of the transmitted beam is obtained through the lower

110 Cassegrain objective. This is used to visualize the beam in focal point of the lower Cassegrain objective during focusing (Fig. 2).

The capabilities of the spectrophotometer are not modified and spectra can be recorded in the range $200-3,000 \mathrm{~nm}$, with a resolution down to $0.1 \mathrm{~nm}$. In the wavelength range $250-2500$ $\mathrm{nm}$, the measurement reproducibility is $<0.1 \mathrm{~T} \%(95 \%$ confidence level) and the measurement 115 accuracy is $<0.5 \mathrm{~T} \%$.

The sample chamber of the microscope and the working distance of the Cassegrain objectives (45 $\mathrm{mm}$ in total) are large enough to accept a microthermometric stage (Linkam ${ }^{\circledR}$ TS1500) which is designed for transmission measurements. By matching the focal points of the two Cassegrain mirrors onto the bottom of the sample through the hole of the ceramic element of the heating stage, optical absorption spectra can be recorded in transmission in the $25^{\circ} \mathrm{C}-1200^{\circ} \mathrm{C}$ temperature range.

\section{Experimental Procedure}

A correction procedure has to be applied on the data set in order to take into account: (i) the variations of emissivity between the two lamps of the spectrometer, (ii) the absorption of the aluminum mirrors, (iii) the efficiency of the detectors and (iv) the sample environment. Two OAS reference spectra are necessary for the correction, one with the light beam going through the sample $\left(\mathrm{I}_{\mathrm{T}}\right)$ and another without any sample in the light beam $\left(\mathrm{I}_{0}\right)$. The optical density (O.D.) is obtained by

130 the relation:

O.D. $=\log _{10}\left(\mathrm{I}_{0} / \mathrm{I}_{\mathrm{T}}\right)($ Eq. 1).

As the emissivity of the furnace cannot be neglected in the IR domain at temperatures above $500^{\circ} \mathrm{C}$, black body emission gives rise to artifacts above this temperature. An additional correction is then necessary. This additional reference spectrum $\left(\mathrm{I}_{\mathrm{F}}\right)$ is recorded by masking the incoming light beam. Optical density is deduced as follows:

O.D. $=\log _{10}\left(\left(\mathrm{I}_{0}-\mathrm{I}_{\mathrm{F}}\right) /\left(\mathrm{I}_{\mathrm{T}}-\mathrm{I}_{\mathrm{F}}\right)\right)$ (Eq. 2).

Spectra are then normalized to the thickness of the sample, leading to a linear absorption coefficient.

At high absorbance, an acceptable signal/noise ratio is obtained for an O.D. $<1.6$, when the 
140 microthermometric stage is included. In addition, the low efficiency of the photomultiplier in the NIR region and of the InGaAs detector in the near visible range, associated with the multiple reflections of the beam on the different mirrors, generates noise in the region corresponding to the detector change between PM and the InGaAs detector (around $800 \mathrm{~nm}$ ). A home made procedure using Igor Pro $6 \AA$ has been developed to correct this drawback.

Optical absorption spectra were obtained on double-face polished crystals (about $50 \mu \mathrm{m}$ thick) which contains glass inclusions. As these inclusions have a size larger than $100 \mu \mathrm{m}$, considering the size of the light beam, light may be transmitted through these inclusions without being absorbed by the crystal matrix. The spectra were recorded in the range 2,500 - $330 \mathrm{~nm}(4,000$ $-30,000 \mathrm{~cm}^{-1}$ ) by using the experimental setup described above, with a $1 \mathrm{~nm}$ resolution and a counting time of $0.8 \mathrm{~s}$ for each step. The optical density was normalized to the thickness of the sample to obtain the absorption coefficient $\left(\mathrm{cm}^{-1}\right)$. The same parameters were used to record the optical spectrum of a basaltic glass synthesized from a natural basalt under controlled reducing conditions $^{12}$ and used as a reference. These volcanic glass inclusions, as well as the basaltic glass are Fe-bearing aluminosilicate glasses whereas the surrounding crystal is an olivine $\left(\mathrm{Mg}_{2} \mathrm{SiO}_{4}: \mathrm{Fe}^{2+}\right)$.

155 Optical absorption spectra have also been recorded on a natural spinel single crystal $\left(\mathrm{MgAl}_{2} \mathrm{O}_{4}\right)$, containing $\mathrm{Fe}^{2+}$ and $\mathrm{Cr}^{3+}$, which is known for being thermochromic ${ }^{9}$. The crystal has been thinned down to $0.5 \mathrm{~mm}$ in order to obtain sufficient transmission for measurement. The measurements were made at controlled temperature between room temperature and $600^{\circ} \mathrm{C}$, with a $100^{\circ} \mathrm{C}$ step, during heating and cooling.

Color evolution during heating and cooling has been quantified using the $\mathrm{L}^{*} \mathrm{a} * \mathrm{~b} *$ coefficients in the colorimetric system defined in 1976 by the International Commission on Illumination $(\mathrm{CIE})^{13}$. The determination of the $\mathrm{L}^{*}, \mathrm{a}^{*}$ and $\mathrm{b}^{*}$ coefficients was made from the transmission spectra obtained, at every $5 \mathrm{~nm}$ from 380 to $780 \mathrm{~nm}$. A $10^{\circ}$-view angle and the CIE standard illuminant D65 (indirect sunlight at 6,500 K) were used as measurement conditions. These data are presented in an $a^{*}-b^{*}$ diagram ${ }^{14}$. They have also been converted to $\mathrm{x}$ and $\mathrm{y}$ coefficients to be presented in a chromaticity diagram.

\section{Applications}

A specific case of microscopic scale investigations is illustrated by natural glass inclusions in minerals, used as a witness of volcanic processes. The study of these small pieces of quenched natural melts has been significantly improved using microspectroscopic techniques such as $\mu$ - 
175 Raman, $\mu$-FTIR ${ }^{15}$ or $\mu$-X-ray absorption techniques ${ }^{16}$, which provide information on the speciation of transition elements in natural magmas. Silicate melt droplets are, indeed, usually entrapped during crystal growth and preserved upon cooling as minute glass inclusions. These inclusions record important geochemical parameters, such as primary magma composition, volatile speciation, depth and temperature of magma storage and nature of open system processes. However, their reduced size, typically around 20 to $100 \mu \mathrm{m}$, preclude the use of OAS, despite the information on coordination and oxidation state of transition elements given by this method ${ }^{17}$.

In this case, both glass inclusion and olivine crystal are bearing $\mathrm{Fe}^{2+}$ and, to a smaller extent, $\mathrm{Fe}^{3+}$ impurities. But, the spectral signature of $\mathrm{Fe}^{2+}$ being different in OAS between the glass and the crystal, it is possible to probe the spectroscopic features of both the inclusion and the crystalline matrix (olivine, $\mathrm{Mg}_{2} \mathrm{SiO}_{4}: \mathrm{Fe}^{2+}$ ). The optical absorption spectrum of inclusion Inc 1, shown in Fig. 3, exhibits in the NIR region a prominent absorption band centered at 9,500 $\mathrm{cm}^{-1}$ and a shoulder at $5,300 \mathrm{~cm}^{-1}$. These absorption bands rise from the presence of $\mathrm{Fe}^{2+}$ in basaltic glasses ${ }^{18}$. Similar absorption bands are observed in the basaltic glass of reference. One weak absorption band is also observed at $18,500 \mathrm{~cm}^{-1}$ and may be interpreted as a spin-forbidden absorption band of $\mathrm{Fe}^{3+}$. In the

$190 \mathrm{UV}$, the absorption edge is associated to the presence of an oxygen to iron charge transfer (OMCT). The olivine spectrum (Fig. 3) also shows three intense and rather narrow absorption bands in the NIR region, associated with the presence of $\mathrm{Fe}^{2+}$ in the distorted octahedral sites of the olivine structure, $\mathrm{M} 1$ and $\mathrm{M} 2{ }^{19}$. As the position and width of these bands are different between the glass inclusion and the host olivine crystal, the optical absorption spectrum of Inc 1 indicates the spatial

195 selectivity of the experimental setup. Moreover, the weak absorption bands associated with spinforbidden $\mathrm{Fe}^{2+}$ transitions, observable in the visible region in the olivine spectrum, have positions and shapes different from the $\mathrm{Fe}^{3+}$ weak absorption band of the inclusion spectrum, confirming the absence of significant contribution from the olivine. The efficiency of micro-focusing, expected from the relative size of the spot and the glass inclusion (Fig.2, b and c) is demonstrated over the sample depth by the absence of features arising from the surrounding olivine crystal and confirmed by the similarity between the inclusion spectrum and the spectrum of a basaltic glass.

\section{Microspectrophotometry at High-Temperature}

The evolution of spectral properties with temperature is illustrated by the optical absorption spectra of a spinel crystal $\left(\mathrm{MgAl}_{2} \mathrm{O}_{4}\right)$ containing $\mathrm{Fe}^{2+}$ and $\mathrm{Cr}^{3+}$ impurities (Fig. 4).

Spinel spectra show the absorption bands expected for $\mathrm{Fe}^{2+}$ and $\mathrm{Cr}^{3+}$ substituted to $\mathrm{Mg}^{2+}$ and $\mathrm{Al}^{3+}$ respectively. The absorption band around $18,000 \mathrm{~cm}^{-1}$ and the other at $26,000 \mathrm{~cm}^{-1}$ with a shoulder at $24,000 \mathrm{~cm}^{-1}$ indicate $\mathrm{Cr}^{3+}$ transitions in distorted octahedral environment ${ }^{9}$. The 
210 absorption band observed at $5,000 \mathrm{~cm}^{-1}$ is due to tetrahedral $\mathrm{Fe}^{2+20}$. Two additional weak and narrow bands, due to $\mathrm{Cr}^{3+}$ spin-forbidden transitions are observed at $14,500 \mathrm{~cm}^{-1}$ and $29,500 \mathrm{~cm}^{-1}$. The possibility to observe these absorption bands evidence the good sensitivity and resolution of the setup.

The thermochromism of the spinel arises from the shift toward the NIR of the two main

215 absorption bands observed in the visible region with increasing temperature. The decreasing energy of the $\mathrm{Cr}^{3+}$ absorption bands with increasing temperature is related to an increasing $\mathrm{Cr}-\mathrm{O}$ distance due to thermal expansion of the crystal structure. The intensity of the absorption of the centrosymmetric site of $\mathrm{Cr}^{3+}$ is increasing with increasing temperature due to dynamic removal of the inversion center by vibronic coupling with odd vibrations. As shown in Fig. 5, this shift results

220 in an evolution of the color from pink to green (see also Table I), as observed earlier'. This illustrates the possibility of following color changes with temperature using this setup.

The reproducibility of the measurements is illustrated by the superposition of the spectra recorded at the same temperature during heating and during cooling (Fig. 4). This demonstrates the absence of significant oxidation during heating.

225

\section{Conclusion}

Measurements of UV-visible-near IR spectra using a new microspectrophotometer based on a microscope using a Schwarzschild-type Cassegrain optics demonstrate its capability for

230 investigating optical absorption spectra at the $\mu \mathrm{m}$ scale. This is of special importance for investigating optical absorption spectra over a broad range, without perturbations from chromatic aberrations from a conventional microscope setup. This allows to investigate spectral properties of transition elements in minute synthetic or natural materials, glassy or crystalline. The versatility of this experimental setup, due to the large size of the sample compartment, will be used for

235 investigating the evolution of optical absorption spectra under high/low temperature and possibly pressure conditions.

\section{Acknowledgements}

240 We thank Nicole Métrich for providing the natural sample containing the glass inclusions investigated in this study. We also thank the two anonymous reviewers for helping to improve the quality of the manuscript. 
1. E.R. Blout, G.R. Bird. "Infrared Microspectroscopy .2.” J. Opt. Soc. Am. 1951. 41(8): 547551.

2. H.J. Humecki. Practical Guide to Infrared Microspectroscopy. New York, USA: CRC Press, 1995.

3. A.W. Coleman, M.J. Maguire, J.R. Coleman. "Mithramycin- and 4'-6-Diamidino-2Phenylindole (DAPI)-DNA Staining for Fluorescence Microspectrophotometric Measurement of DNA in Nuclei, Plastids, and Virus Particles”. J. Histochem. Cytochem. 1981. 29(8): 959968.

4. V.I. Govardovskii, N. Fyhrquist, T. Reuter, D.G. Kuzmin, K. Donner. "In search of the visual pigment template". Vis. Neurosci. 2000. 17(4): 509-528.

5. D.R. Cousins, C.R. Platoni, L.W. Russell. "The Use of Microspectrophotometry for the Identification of Pigments in Small Paint Samples”. Forensic Sci. Int. 1984. 24(3): 183-196.

6. R. Near, C. Tabor, J. Duan, R. Pachter, M. El-Sayed. "Pronounced Effects of Anisotropy on Plasmonic Properties of Nanorings Fabricated by Electron Beam Lithography”. Nano Lett. 2012. 12(4): 2158-2164.

7. Y. Yamanoi, S. Nakashima. "In Situ High-Temperature Visible Microspectroscopy for Volcanic Materials". Appl. Spectrosc. 2005. 59(11): 1415-1419.

8. P. Mouroulis, B. van Gorp, D. Blaney, R.O. Green. "Reflectance Microspectroscopy of Natural Rock Samples in the Visible and Near Infrared”. Appl. Spectrosc. 2008. 62(12): 1370-1377.

9. M.N. Taran, K. Langer, A.N. Platonov, V. Indutny. "Optical Absorption Investigation of $\mathrm{Cr}^{3+}$ Ion-Bearing Minerals in the Temperature Range 77-797 K”. Phys. Chem. Miner. 1994. 21(6): 360-372.

10. K. Ullrich, K. Langer, K.D. Becker. "Temperature Dependence of the Polarized Electronic Absorption Spectra of Olivines. Part I - Fayalite”. Phys. Chem. Miner. 2002. 29(6): 409-419.

11. L. Kido, M. Mueller, C. Ruessel. "Redox Reactions during Temperature Change in SodaLime-Silicate Melts Doped with Copper and Iron or Copper and Manganese”. J. Non-Cryst. Solids. 2006. 352(38-39): 4062-4068.

12. M. Bonnin-Mosbah, A.S. Simionovici, N. Métrich, J.-P. Duraud, D. Massare, P. Dillmann. "Iron Oxidation States in Silicate Glass Fragments and Glass Inclusions with a XANES Micro-Probe". J. Non-Cryst. Solids. 2001. 288(1-3): 103-113.

13. G. Wyszecki, W.S. Stiles. Color Science: Concepts and Methods, Quantitative Data and Formulae. Chichester, UK: John Wiley \& Sons, 2008. 2nd ed.

14. C. Onga, S. Nakashima. "Darkfield Reflection Visible Microspectroscopy Equipped with a 
Color Mapping System of a Brown Altered Granite”. Appl. Spectrosc. 2014. 68(7): 740-748.

15. N. Métrich, P.J. Wallace. "Volatile Abundances in Basaltic Magmas and Their Degassing Paths Tracked by Melt Inclusions”. Rev. Mineral. Geochem. 2008. 69(1): 363-402.

16. M. Bonnin-Mosbah, N. Métrich, J. Susini, M. Salome, D. Massare, B. Menez. "Micro X-Ray Absorption Near Edge Structure at the Sulfur and Iron K-Edges in Natural Silicate Glasses". Spectrochim. Acta Part B At. Spectrosc. 2002. 57(4): 711-725.

17. G.R. Rossman. “Optical Spectroscopy”. Rev. Mineral. Geochem. 2014. 78(1): 371-398.

18. W.E. Jackson, F. Farges, M. Yeager, P.A. Mabrouk, S. Rossano, G.A. Waychunas, et al. "Multi-Spectroscopic Study of Fe(II) in Silicate Glasses: Implications for the Coordination Environment of Fe(II) in Silicate Melts”. Geochim. Cosmochim. Acta. 2005. 69(17): 43154332.

19. R.G. Burns. Mineralogical Applications of Crystal Field Theory. Cambridge, UK: Cambridge University Press, 1993. 2nd ed.

20. G.R. Rossman, M.N. Taran. "Spectroscopic Standards for Four- and Fivefold-Coordinated Fe ${ }^{2+}$ in Oxygen-Based Minerals”. Am. Mineral. 2001. 86(7-8): 896-903.

\section{Figure captions}

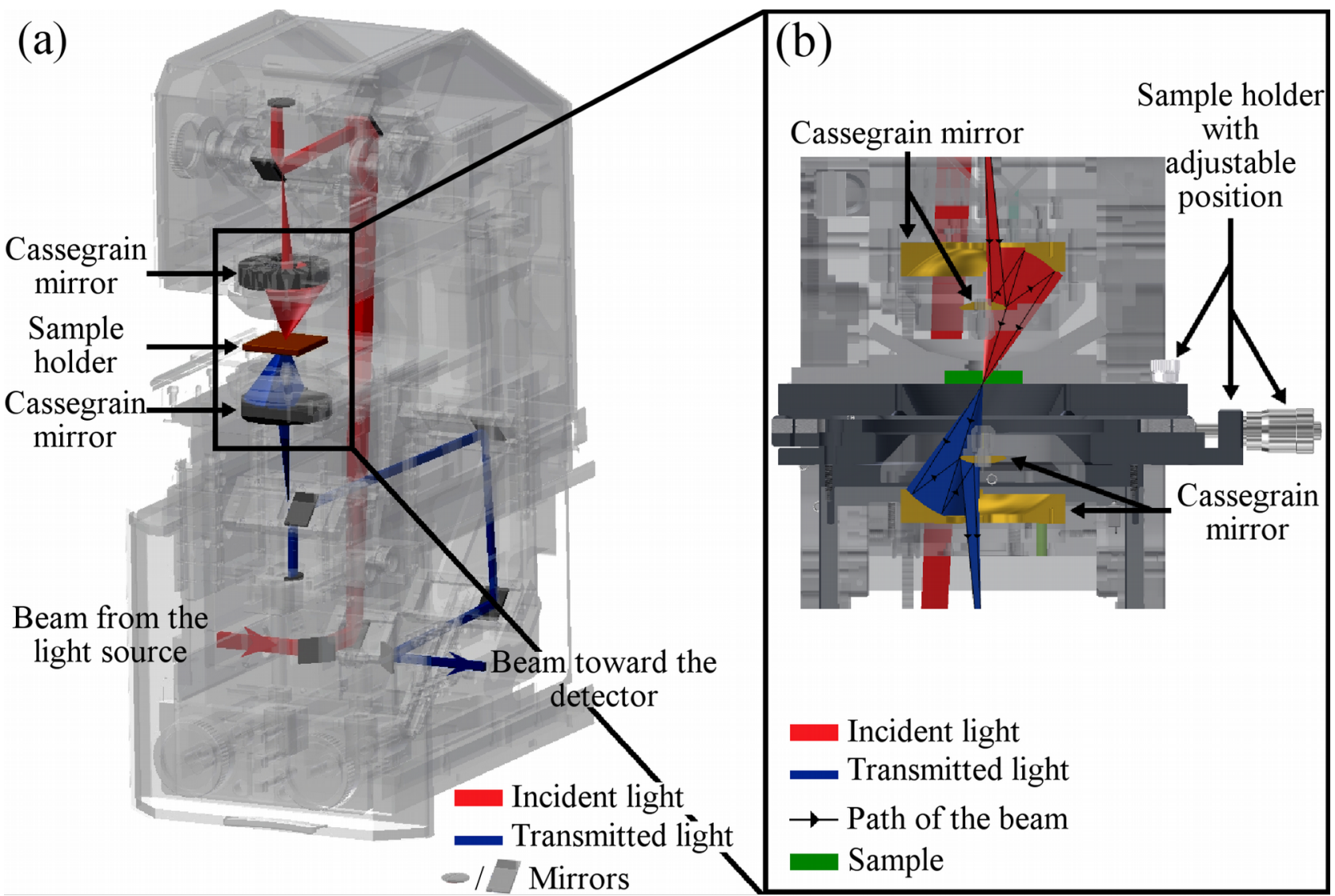


blue) light beam through the microscope. 


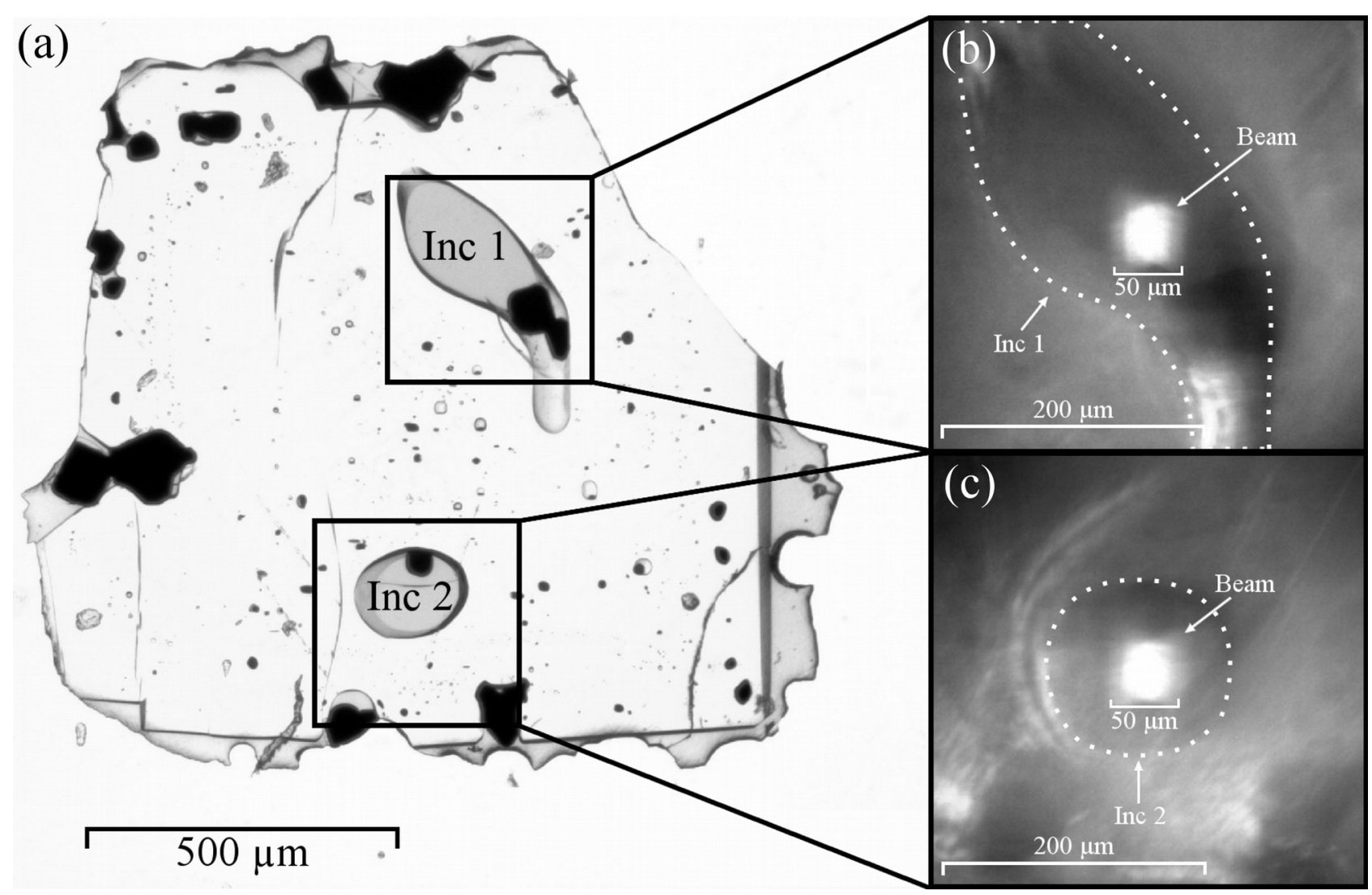

Fig. 2: (a) Optical microscope photography of an olivine crystal sample containing two volcanic glass inclusions (Inc 1 and Inc 2) ; (b) and (c): Photographs of glass inclusions Inc 1 and Inc 2, respectively, viewed from the camera of the micro-focalized spectrophotometer. Inclusions are highlighted with white dashed contours, the bright spot evidence the position of the beam inside the inclusions.

260

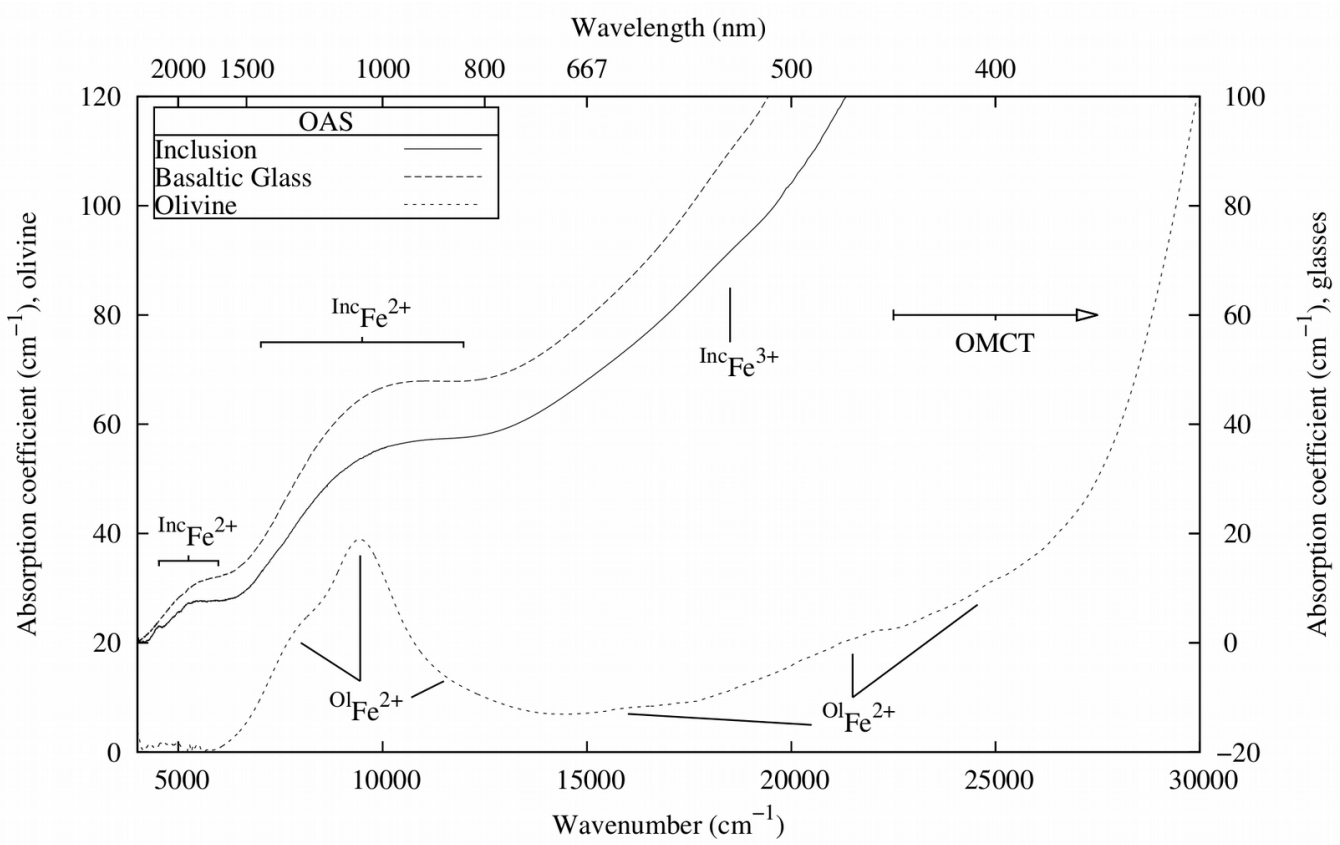

270 Fig. 3: $\mu$-Optical absorption spectra of glass inclusions Inc 1, of the surrounding olivine crystal and 
of a basaltic glass in the range 4,000-30,000 $\mathrm{cm}^{-1}$. Data are cut at $120 \mathrm{~cm}^{-1}$ to better observe the absorption bands in the IR. The positions of the absorption bands originating from the olivine and the inclusions (or basaltic glass) are referred to as ${ }^{\mathrm{Ol}} \mathrm{Fe}$ and ${ }^{\mathrm{Inc}} \mathrm{Fe}$, respectively.

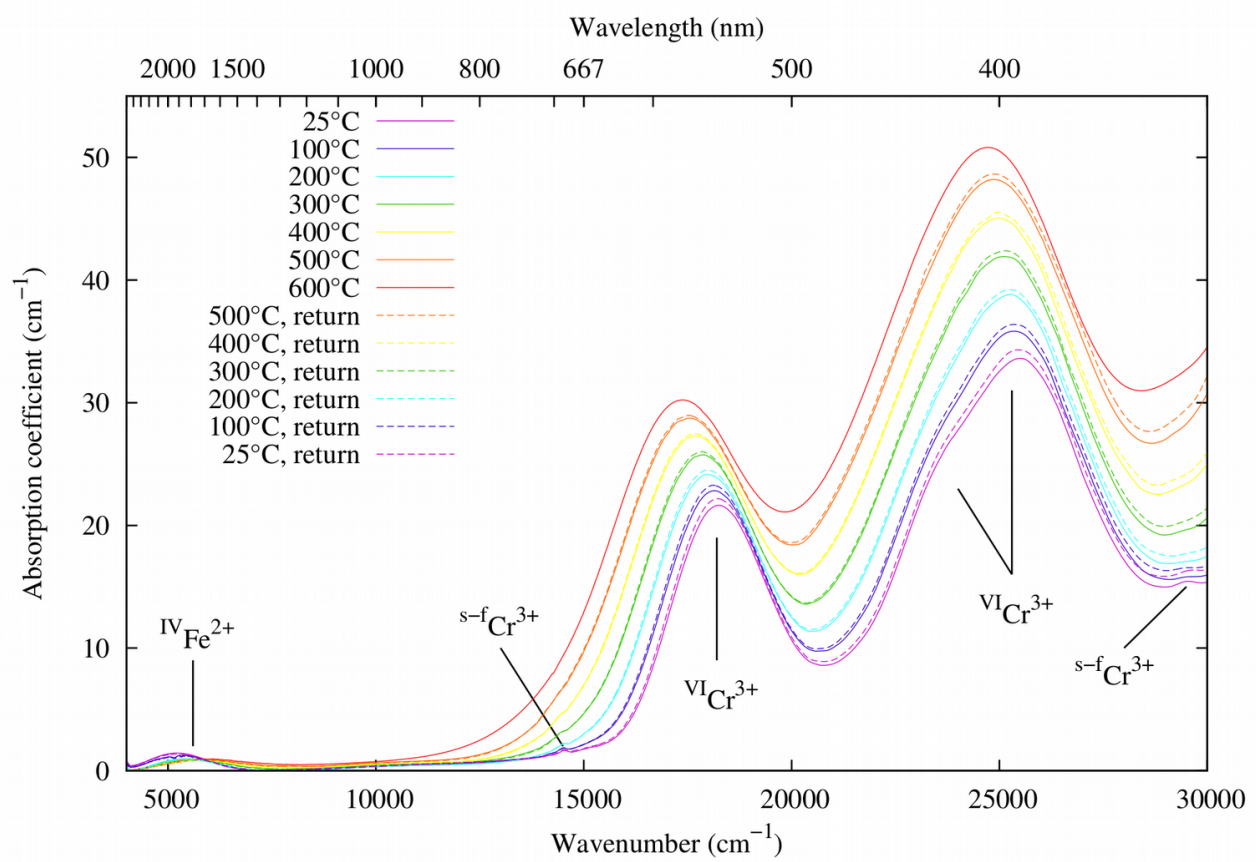

Fig. 4: $\mu$-Optical absorption spectra measured between room temperature and $600^{\circ} \mathrm{C}$ on a natural spinel crystal $\left(\mathrm{MgAl}_{2} \mathrm{O}_{4}\right)$ containing $\mathrm{Fe}^{2+}$ and $\mathrm{Cr}^{3+}$ impurities. The crystal is $0.5 \mathrm{~mm}$ thick. The spectra denoted "return" are recorded during cooling, after heating at $600^{\circ} \mathrm{C}$. The coordination of the cation at the origin of each band is indicated, s-f stands for spin-forbidden transition.
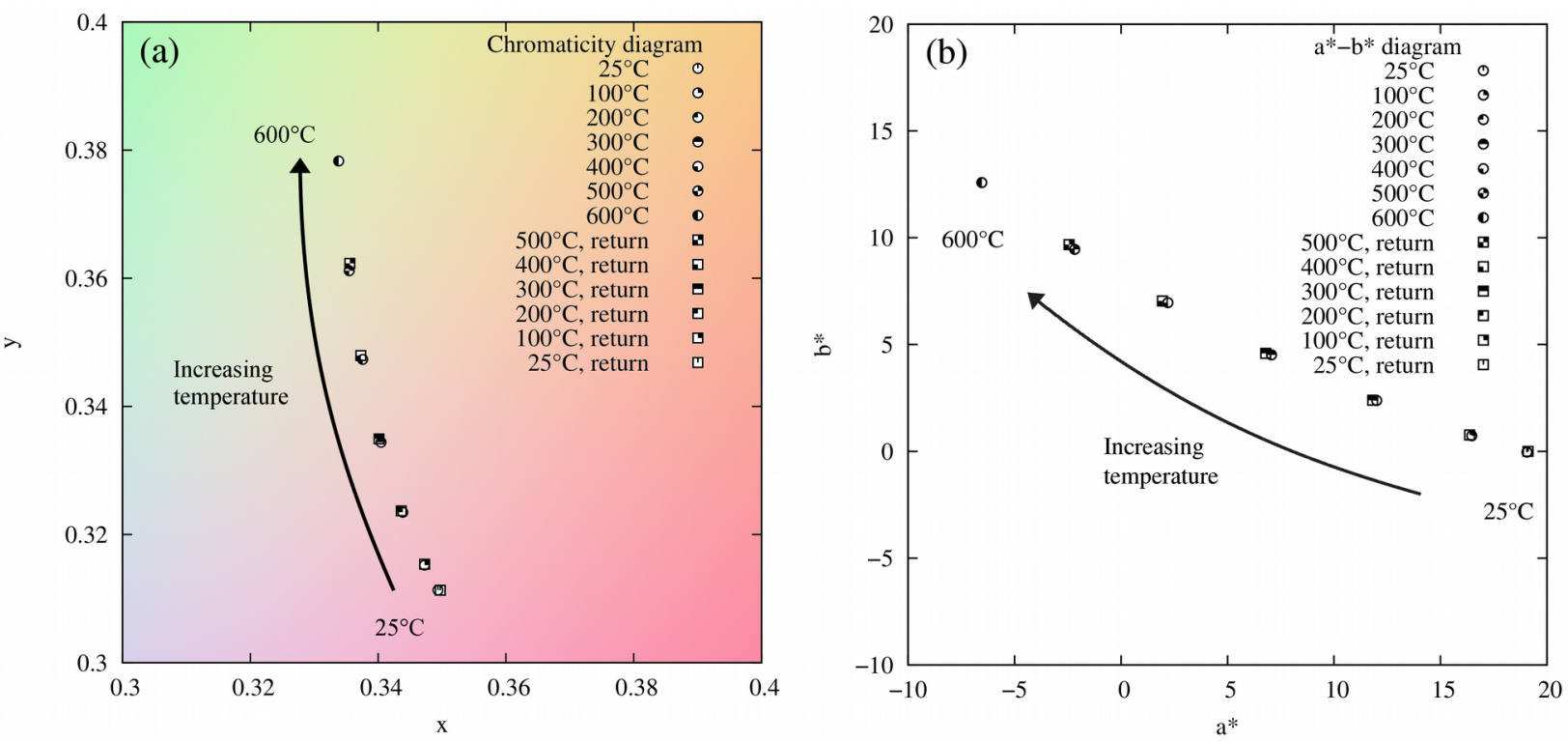

Fig. 5: Evolution of the color of the spinel crystal with increasing temperature from $25^{\circ} \mathrm{C}$ to $600^{\circ} \mathrm{C}$ shown on a chromaticity diagram (a) and on an $a^{*}-b^{*}$ diagram (b). The spectra denoted "return" are recorded at the given temperature after heating at $600^{\circ} \mathrm{C}$. 
Table

\begin{tabular}{cccccccc}
\hline Temperature & $25^{\circ} \mathrm{C}$ & $100^{\circ} \mathrm{C}$ & $200^{\circ} \mathrm{C}$ & $300^{\circ} \mathrm{C}$ & $400^{\circ} \mathrm{C}$ & $500^{\circ} \mathrm{C}$ & $600^{\circ} \mathrm{C}$ \\
\hline $\mathrm{L}^{*}$ & 61.70 & 59.76 & 57.25 & 54.70 & 52.36 & 50.16 & 48.38 \\
$\mathrm{a}^{*}$ & 19.06 & 16.46 & 12.00 & 7.06 & 2.20 & -2.18 & -6.53 \\
$\mathrm{~b}^{*}$ & -0.04 & 0.73 & 2.38 & 4.51 & 6.96 & 9.46 & 12.58 \\
\hline Temperature & $500^{\circ} \mathrm{C}$, return & $400^{\circ} \mathrm{C}$, return & $300^{\circ} \mathrm{C}$, return & $200^{\circ} \mathrm{C}$, return & $100^{\circ} \mathrm{C}$, return & $25^{\circ} \mathrm{C}$, return \\
\hline $\mathrm{L}^{*}$ & 49.96 & 52.18 & 54.52 & 57.03 & 59.49 & 61.40 \\
$\mathrm{a}^{*}$ & -2.44 & 1.94 & 6.79 & 11.82 & 16.37 & 19.11 \\
$\mathrm{~b}^{*}$ & 9.68 & 7.04 & 4.59 & 2.39 & 0.77 & 0.00
\end{tabular}

Table I: $\mathrm{L}^{*}, \mathrm{a}^{*}$ and $\mathrm{b}^{*}$ values of the spinel crystal studied at temperatures between $25^{\circ} \mathrm{C}$ and $600^{\circ} \mathrm{C}$. 300 "return" means that the values are given after heating at $600^{\circ} \mathrm{C}$. 